\title{
Configurações
}

Revista Ciências Sociais

$27 \mid 2021$

Vária

\section{Consumo de álcool e alcoolismo durante a Guerra Colonial Portuguesa. Uma perspetiva antropológica}

Alcohol use and alcoholism during the Portuguese Colonial War. An

anthropological perspective

Consommation d'alcool et alcoolisme pendant la Guerre coloniale portugaise.

Une perspective anthropologique

\section{Vasco Gil Calado}

\section{(Q) OpenEdition}

\section{Journals}

Edição electrónica

URL: https://journals.openedition.org/configuracoes/11733

DOI: 10.4000/configuracoes.11733

ISSN: 2182-7419

\section{Editora}

Centro de Investigação em Ciências Sociais

\section{Edição impressa}

Paginação: 5-21

ISSN: 1646-5075

\section{Refêrencia eletrónica}

Vasco Gil Calado, «Consumo de álcool e alcoolismo durante a Guerra Colonial Portuguesa. Uma perspetiva antropológica», Configurações [Online], 27 | 2021, posto online no dia 24 junho 2021 , consultado o 26 junho 2021. URL: http://journals.openedition.org/configuracoes/11733 ; DOI: https:// doi.org/10.4000/configuracoes. 11733 
Calado, Vasco Gil - Consumo de álcool e alcoolismo durante a Guerra Colonial Portuguesa. Uma perspetiva antropológica, Configurações, vol. 27, 2021, pp. 5-21.

\title{
Consumo de álcool e alcoolismo durante a Guerra Colonial Portuguesa. Uma perspetiva antropológica
}

VASCO GIL CALADO *

Serviço de Intervenção nos Comportamentos Aditivos e nas Dependências (SICAD)

\begin{abstract}
Resumo
Com base nos usos de bebidas alcoólicas por parte dos militares portugueses que participaram na Guerra Colonial Portuguesa (1961-1974), discute-se a importância da dimensão social, sem a qual não se consegue compreender os contornos do consumo e as motivações dos consumidores. De acordo com os dados recolhidos, durante o conflito, a ingestão de bebidas alcoólicas era particularmente frequente e intensa, sendo a embriaguez uma prática reiterada e tendencialmente tolerada e desvalorizada pelas autoridades militares. No contexto de guerra, os excessos alcoólicos eram encarados como algo normal e não a partir da perspetiva da patologia, decorrendo do contex to e das difíceis circunstâncias sociais.
\end{abstract}

Palavras-chave: Consumo de álcool, Guerra Colonial Portuguesa, Experiência de guerra, Antropologia da Saúde.

\begin{abstract}
Alcohol use and alcoholism during the Portuguese Colonial War. An anthropological perspective

Based on the use of alcoholic beverages among the Portuguese military who participated in the Portuguese Colonial War (1961-1974), the importance of the social perspective is discussed, without which one cannot understand the contours of consumption and the motivations of consumers. According to the data collected, during the conflict the consumption of alcoholic beverages was particularly high and drunkenness was a frequent practice that tended to be tolerated and devalued by the military authorities. In the context of war, excessive alcohol was seen as normal and not from a medical perspective, given the context and the harsh social circumstances.
\end{abstract}

Keywords: Alcohol consumption, Portuguese Colonial War, War experience, Medical Anthropology. 


\section{Résumé \\ Consommation d'alcool et alcoolisme pendant la Guerre coloniale portugaise. Une perspective anthropologique}

Sur la base de l'utilisation des boissons alcoolisées par les militaires portugais qui ont participé à la Guerre coloniale portugaise (1961-1974), nous discutons de l’importance de la dimension sociale, sans laquelle il est impossible de comprendre les contours de la consommation et les motivations des consommateurs. Selon les données recueillies, pendant le conflit, la consommation de boissons alcoolisées était particulièrement fréquente et intense, l'ivresse étant une pratique répétée qui avait tendance à être tolérée et dévalorisée par les autorités militaires. Dans le contexte de la guerre, les excès alcooliques étaient considérés comme quelque chose de normal et non du point de vue de la pathologie, en raison du contexte et des circonstances sociales difficiles.

Mots-clés: Consommation d'alcool, Guerre coloniale portugaise, Expérience de guerre, Anthropologie de la Santé.

\section{Introdução}

Este artigo constitui uma análise da dimensão e dos contornos do consumo de álcool ${ }^{1}$ na Guerra Colonial Portuguesa (1961-74) - um conflito que se prolongou por mais de uma década nos territórios de Angola, Moçambique e GuinéBissau e mobilizou mais de um milhão de militares portugueses, a maioria de origem rural, pouco letrada e com idades a rondar os 20 anos - e uma discussão do uso de bebidas alcoólicas à luz de uma perspetiva antropológica, por oposição à visão hegemónica, de natureza biomédica.

As Ciências Médicas consideram que determinados padrões de consumo de bebidas alcoólicas configuram uma doença (aquilo que normalmente se denomina «alcoolismo») e taxativamente concebem a pessoa que ingere álcool de determinada maneira e com determinadas consequências como um doente, com base em tipologias como «consumo nocivo», «dependência de álcool»ou «perturbação do uso do álcool» (Pinto et al., 2016), a partir das quais é possível fazer um diagnóstico clínico, nomeadamente através de instrumentos de rastreio $^{2}$. Esta visão da dependência alcoólica e do consumo considerado «nocivo» assenta, em grande medida, na ideia de descontrolo e compulsão (Reinarman

$1 \mathrm{O}$ presente texto é resultado de um trabalho mais vasto que conduziu a um doutoramento em Antropologia em 2019, com uma tese sobre o consumo de substâncias psicoativas entre os militares portugueses que participaram no conflito - aqui entendidos como todos os que estiveram ao serviço das forças armadas portuguesas, incluindo os africanos que foram recrutados localmente (Calado, 2019). É considerado apenas o consumo de bebidas alcoólicas, deixando de fora outros temas discutidos na dissertação, nomeadamente o uso de cannabis.

2 Entre os instrumentos auxiliares de diagnóstico de problemas ligados ao álcool, destacam-se o AUDIT e o ASSIST, testes em forma de escalas que permitem identificar o nível de risco e o caráter nocivo dos consumos. 
e Granfield, 2015), conceitos-chave para a conceção biomédica de qualquer comportamento aditivo.

Por outro lado, há uma extensa bibliografia, proveniente predominantemente da área das Ciências Sociais, que propõe uma visão diferente daquela que a biomedicina e, por arrasto, o senso comum hoje e $^{3}$ êm destes fenómenos. De natureza tendencialmente holística, a perspetiva socializante releva a dimensão coletiva e encara o que muitas vezes é visto como uma enfermidade pessoal (designadamente uma desordem ou um transtorno de âmbito biológico, mental ou comportamental) como algo que, em grande medida, decorre do contex to e das circunstâncias socioculturais, e não tanto das características individuais e de eventuais predisposições genéticas do consumidor (Heath, 2000; 1987). Privilegia-se, portanto, um olhar social perante um comportamento individual que, em última instância, configura uma escolha pessoal, como o é ingerir bebidas alcoólicas em grandes quantidades e de forma recorrente, na medida em que se assume que é no plano societal que a prática é enquadrada, definida, explicada, problematizada, regulada, incentivada ou sancionada, nomeadamente por via de normas, valores, representações, leis e sanções.

Entre as Ciências Sociais, destacam-se as disciplinas da Antropologia e da História, que, por via da perspetiva comparativista e da perspetiva diacrónica, respetivamente, demonstram que os padrões de consumo e as tipologias de consumidores, bem como os efeitos e até as consequências da ingestão de bebidas alcoólicas, variam consideravelmente de cultura para cultura e mesmo, numa única sociedade, assumiram formas diferentes e múltiplas em tempos passados (Hunt e Barker, 2001). Isto é, no que concerne ao uso de bebidas alcoólicas, o que é tomado como certo em determinada sociedade frequentemente não se aplica a outras sociedades e é sempre resultado de processos históricos, sociais e políticos. A figura do dependente alcoólico e o comportamento que hoje nas sociedades ocidentais se associa à embriaguez não só não são universais como não se verificavam nos mesmos moldes, por exemplo na Europa da Idade Média (Levine, 1978). Nesse sentido, defende-se que os padrões de consumo de bebidas alcoólicas dependem de processos de socialização, isto é, são apreendidos e reproduzidos socialmente (Schneider, 2015), uma postulação que o modelo aditivo não reconhece suficientemente. De facto, apesar de a posição biomédica assumir que os comportamentos aditivos são fenómenos multifatoriais, salientando a necessidade de adotar uma perspetiva biopsicossocial, frequentemente a dimensão social é menosprezada ou simplesmente ignorada.

3 Nem sempre em Portugal se olhou para os padrões de consumo de álcool de risco acrescido como fenómenos do foro da saúde e da doença. Nas décadas de 60 e 70 do século XX, quando a Guerra Colonial Portuguesa teve lugar, os «excessos» alcoólicos tendiam a ser vistos como algo normal, um hábito cultural profundamente enraizado na sociedade portuguesa (Mano, 1990). 
O que neste aspeto se passou na Guerra Colonial Portuguesa é aqui tomado como um exemplo empírico da importância da vertente sociocultural. A realidade a seguir discutida reforça a ideia de que olhar para o uso e o abuso (para usar a terminologia biomédica mais normativa) de bebidas alcoólicas com base exclusivamente em critérios clínicos e classificatórios é necessariamente redutor. O principal argumento subjacente ao presente texto é o de que, apesar de haver na ingestão de bebidas alcoólicas uma inegável vertente biológica - afinal, o álcool e as outras drogas definem-se precisamente por desencadearem processos químicos que resultam em efeitos psicoativos -, a dimensão social não deve ser negligenciada, sob pena de se obter um retrato parcial, que tende a ignorar a racionalidade do consumidor, nomeadamente aqueles que bebem de modo «excessivo» ou «nocivo». Na Guerra Colonial Portuguesa os padrões de consumo de álcool dos militares portugueses derivavam das suas características sociodemográficas (sexo, idade, origem e condição social, por exemplo) e sobretudo das circunstâncias socioculturais, particularmente adversas.

\section{Método}

Entre 2015 e 2016, com o objetivo de caracterizar e enquadrar o consumo de bebidas alcoólicas na Guerra Colonial Portuguesa, foram realizadas entrevistas em profundidade com antigos militares das forças armadas portuguesas que participaram no conflito $(\mathrm{N}=17)$, procedendo-se em simultâneo a uma extensa pesquisa documental. Num momento mais tardio, dada a necessidade de complementar a informação recolhida, foi lançado um inquérito online dirigido a ex-combatentes da Guerra Colonial Portuguesa $(\mathrm{N}=210)$ e procedeu-se a uma etnografia de ciberespaços frequentados por estes, designadamente comunidades eletrónicas e blogues. Reunida toda a informação, esta foi analisada segundo a lógica da triangulação (Griffiths e Mounteney, 2010; Denzin, 2009).

Os veteranos da Guerra Colonial Portuguesa ${ }^{4}$ foram entrevistados de uma forma semi-estruturada (Fontana e Frey, 2005), de acordo com os princípios da entrevista etnográfica (Devillard, Mudanó e Pazos, 2012; Bernard, 2006), dado que se pretendia, acima de tudo, entender os consumos dos antigos militares a partir das suas próprias categorias e significações. Os entrevistados foram recrutados seguindo o método bola de neve (Fernandes e Carvalho, 2000), tendo como ponto de partida dois contactos iniciais ${ }^{5}$. Procurou-se que esta rede informal de informantes apresentasse a maior diversidade possível, tanto no que diz respeito ao território em que o serviço militar decorreu, como no que respeita à patente, função ou ramo militar - alguns informantes serviram como

\footnotetext{
4 Todos os entrevistados são citados sob pseudónimo.

5 Para uma discussão mais detalhada acerca das incidências metodológicas da pesquisa, incluindo o processo (e as dificuldades) de recrutamento dos informantes, remete-se para Calado (2019: 25-32).
} 
soldados ou cabos e outros como graduados (furriéis e alferes), uns tiveram funções administrativas e técnicas e outros funções operacionais (incluindo alguns pertencentes às chamadas «tropas especiais»), uns envolveram-se ativamente em combate e outros não chegaram a disparar um tiro, etc. ${ }^{6}$. Assim sendo, do ponto de vista militar, a principal característica comum a todos é terem participado na Guerra Colonial Portuguesa enquanto milicianos, pelo que a participação no conflito significou uma interrupção na sua vida civil, à qual regressaram uma vez terminada a comissão em África. À data da entrevista, o perfil sociodemográfico dos informantes era bastante heterogéneo ${ }^{7}$, tal como a sua orientação política ou o seu posicionamento em relação à guerra em que participaram. Contudo, é importante deixar claro que, graças à diversidade de experiências de guerra, a rede informal de informantes é aqui tomada como representante dos ex-combatentes da Guerra Colonial Portuguesa, mas de maneira nenhuma como representativa.

À parte um enquadramento histórico e militar, a pesquisa documental incidiu sobretudo num conjunto de 34 textos de cariz (exclusiva ou parcialmente) autobiográfico sobre a experiência militar, incluindo diários e coletâneas de aerogramas enviados diretamente da guerra. Estas memórias sobre a Guerra Colonial Portuguesa escritas na primeira pessoa serviram de contraponto às entrevistas realizadas, dado que permitiram ter acesso a informação em falta (a perspetiva de um médico militar ou de um capitão, por exemplo), bem como caracterizar a importância que, para os ex-combatentes, o álcool teve na sua experiência de guerra (na medida em que as referências sobre o assunto em documentos escritos não nasceram de uma inquirição ativa mas antes do facto de o autor considerar o tema relevante).

Com o inquérito online procurou-se sobretudo obter informação quantitativa e qualitativa sobre o impacto da experiência de guerra e perceber se o consumo de bebidas alcoólicas durante o conflito estava, de algum modo, relacionado com o stress e a ansiedade, uma ideia que emergira durante as entrevistas e a leitura de tex tos autobiográficos. Por seu lado, seguindo os princípios da Antropologia Digital (Pink et al., 2015; Horst e Miller, 2012), uma observação não participante em fóruns eletrónicos de discussão, nomeadamente grupos de Facebook, permitiu assistir à interação sem mediação de ex-combatentes, contribuindo, assim, para esclarecer informação, levantar novas questões ou simplesmente tomar maior conhecimento com a iconografia ou o jargão da época.

6 Outro caminho possível, igualmente válido, seria limitar a análise a elementos de um grupo mais homogéneo, como, por exemplo, os membros de um mesmo batalhão ou companhia militar, os membros de grupo de autoajuda ou de uma associação de veteranos de guerra. No entanto, apesar de resolver alguns problemas metodológicos, esta ideia foi abandonada por se ter privilegiado a diversidade de experiências de guerra.

7 As exceções são sexo e idade, dado que os informantes são todos do sexo masculino e de idade aproximada (sexagenários ou septuagenários). 


\section{Experiência de guerra}

A premissa básica que sustenta a maioria das abordagens antropológicas é: para compreender determinado fenómeno ou realidade social, é necessário analisar o contex to sociocultural, bem como o que fundamenta a agência individual, isto é, as crenças, as motivações e as representações dos atores sociais. Só assim é possível aceder à rede de significados e ao sentido atribuído aos comportamentos individuais.

Mesmo tendo em consideração que a Guerra Colonial Portuguesa foi um conflito que envolveu diretamente mais de um milhão de efetivos e se prolongou por mais de uma década em vários territórios de Angola, Moçambique e Guiné-Bissau, em contextos militares e sociais muito diferentes (o que se traduziu necessariamente num conjunto muito diverso de experiências de guerra), cruzando toda a informação disponível é possível encontrar eixos comuns, e assim, de alguma forma, formular generalizações ${ }^{8}$. Num tex to anterior (Calado, 2016), identificaram-se os traços e as características da Guerra Colonial Portuguesa que ajudam a contextualizar e a compreender a dimensão e os contornos do uso de substâncias psicoativas entre os efetivos portugueses que combateram nas três ex-colónias portuguesas, nomeadamente o facto de ter sido tendencialmente um tempo de experimentação e de contacto com novas realidades, uma experiência feita de grande tensão e estados de constante ansiedade e simultaneamente um contexto de deficiente preparação militar, alguma indisciplina e formas de contestação.

A guerra é, por definição, um contexto-limite, e a participação num conflito armado é uma experiência sempre marcante, frequentemente pontuada pelo medo, pela inquietação e por estados ansiosos. Apesar de, por vezes, a Guerra Colonial Portuguesa ser apontada como uma guerra de escaramuças de acordo com os ex-combatentes, não havia propriamente «linhas da frente» e o contacto com as forças inimigas era, na maior parte dos casos, ocasional e tendencialmente fugaz, sobretudo na forma de emboscadas ou ataques furtivos -, tratou-se de um conflito muito exigente do ponto de vista emocional (Martins, 2015), como são todas as guerras em que se enfrenta uma guerrilha, um inimigo que na maior parte do tempo se esconde e não se vislumbra, que ataca quando não se espera e contra o qual há que estar sempre alerta ${ }^{9}$.

8 Para uma análise histórica, social e militar mais detalhada da Guerra Colonial Portuguesa, remete-se para autores como Cardina e Martins, 2018; Campos, 2017; Afonso e Gomes, 2000; Teixeira, 1998; Antunes, 1995.

9 O ex-alferes miliciano Luís Oeiras (2009: 39) descreve a situação melhor do que ninguém: «um combate de guerrilha é como um terramoto. Pode estoirar em qualquer altura, mas não se pode viver à 
Seguem-se as palavras de três informantes, que descrevem, na primeira pessoa, o quão duro foi ter participado na Guerra Colonial Portuguesa, fosse pelo isolamento, fosse pela violência do quotidiano.

O ex-furriel Bruno Vinhas esteve no Sul de Angola entre 1971 e 1973, numa região onde o $\mathrm{MPLA}^{10}$ não estava militarmente ativo. Segundo ele, mesmo quem não sentia a sua vida ameaçada pelo inimigo, não deixava de se sentir sufocado pelo ambiente «concentracionário», para usar a expressão de António Lobo Antunes (2005: 128), ou o peso do «ostracismo de modorra», para usar a expressão do próprio Vinhas:

"É um corte total e absoluto. Não há telefones, não há telemóveis, não há satélites, não há nada. Há as cartas que vêm. Aquilo é o que se chama o isolamento absoluto de tudo, tudo, tudo, sem rigorosamente mais nada. [...] Nós fomos colocados num dos piores sítios de Angola. Atenção, não em termos de guerra, mas em termos de... Imagine uma paisagem lunar nos confins de tudo o que queira imaginar. A ideia que permite perceber o local é assim: savana desértica encalacrada entre dois desertos, sem nada à volta. [...] Aquilo era um sítio inóspito, longe de tudo. E nós estávamos confinados a um quadrado no meio de coisa nenhuma, no meio de coisa nenhuma!, cercados de arame farpado."

Pelo contrário, Luís Leal, que foi cabo condutor no Norte de Moçambique entre 1971 e 1973, sofreu emboscadas e, inclusivamente, foi ferido em combate. De todos os informantes, é o mais politizado e o mais crítico da posição portuguesa durante a Guerra Colonial. Na verdade, na altura em que foi recrutado, indicou habilitações literárias a menos, o que fez com lhe não fosse atribuído a patente de furriel. Segundo ele, fê-lo para não ter responsabilidades num conflito com que não concordava. Talvez por isso, é o informante que mais se destaca por assumir o caráter traumático da experiência de guerra:

"Tenho memórias vivas, às vezes estou a falar consigo e vêm-me as lágrimas aos olhos. E às vezes quando vejo filmes - eh pá, fogo! -, atéfilmes da guerra do Vietname... Eu tenho lá um filme, que é da Guerra do Vietname - «Corações de Aço», ou o que é que é-, mas assemelha-se tanto à nossa guerra. Eu vejo aquilo tanta vez. Às vezes a minha mulher vai-se deitar, pá, ponho-me ali na sala sozinho, meto aquilo na televisão... eh, eu choro, choro a ver aquilo [emociona-se]. Mas fico aliviado, não sei porquê [enche-se de lágrimas]. A reação

espera debaixo de uma mesa».

10 Durante a Guerra Colonial Portuguesa, o Movimento Popular Libertação de Angola (M PLA) foi um dos movimentos independentistas que se opuseram militarmente às forças armadas portuguesas em Angola, a par da União dos Povos de Angola (UPA) e da União Nacional para a Independência Total de Angola (UNITA). 
que eu tenho é começar a chorar. Começar a lembrar-me daqueles ambientes e começar a chorar. Isso é que ainda não passou. Passado quarenta anos, hein! E depois é isso, sinto-me aliviado quando vejo esse filme. $Q$ ue se assemelha mais ao ambiente que a gente encontrou lá. Terrível, pá. Mas vejo aquele filme e fico aliviado. A minha mulher até diz: «vais ver o filme, não vais?». Então pronto, ela vai-se deitar e eu fico sozinho na sala, choro".

Entre 1971 e 1973, o ex-alferes Miguel Raposo esteve em várias regiões de Moçambique, onde chefiou um grupo de combate de uma «força especial», os comandos. Essa será, porventura, a razão por que foi o informante que mais enfatizou o impacto da violência:

"O meu primeiro tiro de morte foi o meu grande trauma de guerra. Porque não há manuais que expliquem isto... ter que acabar a vida a um rapazinho - que poderia ter sobrevivido, eventualmente podia ter sido amputado. Mas porque era guerrilheiro, supostamente, mandaram-me abatê-lo. E foi muito doloroso. Ter falado com ele, ter estado com ele, ter-lhe prometido a salvação. Insisti e pedi, mas mandaram-me passar o «foxtrot»a «mike» ${ }^{11}$. É duro, é muito duro. E isso traumatizou-me de tal form a que o tiro, o segundo tiro, não consegui. O comandante de companhia pediu-me para atirar: "está a vê-lo? Então atire». "A tire o meu capitão». E o sargento que está ao lado: "não atira um, então atiro eu.». Isso é muito doloroso, não vem nos manuais. É terrível, é terrivel".

Também nos textos biográficos analisados o cenário é tido como muito violento e difícil de suportar, nomeadamente do ponto de vista emocional. A isto há a juntar uma série de adversidades, como a falta de condições materiais existentes na grande maioria dos aquartelamentos portugueses, a deficiente preparação militar ou o mau estado do armamento e restante equipamento; tudo isso terá contribuído, em muitos casos, para um ambiente de saturação, com episódios de indisciplina, desleixo, incúria e contestação. De uma forma geral, com o decorrer dos anos, a desvinculação das tropas à cadeia de comando foi claramente aumentando, à medida que um número crescente de militares punha em causa a justeza do conflito, sentindo-se «carne para canhão», como bem espelha o Cancioneiro do Niassa ${ }^{12}$. Mais do que a «pátria» ou o «dever patriótico», o que guiava os militares portugueses era o conceito de

11 Em alfabeto fonético militar, «passar o foxtrot a mike» quer dizer «passar o ferido a morto». 12 Tendo surgido perto do fim da década de 60 do século XX, em Moçambique, o Cancioneiro do Niassa é um conjunto de adaptações de músicas em voga na altura, cujas letras originais foram substituídas por outras, que, numa tónica humorística e sarcástica, abordavam de forma contundente, e às vezes até violenta, as duras condições de vida dos militares da Guerra Colonial Portuguesa. 
«camaradagem» (Silva, 2007); assim, o propósito último da maioria era simplesmente sobreviver à comissão e, no fim, chegar a casa sã e salva.

As respostas ao inquérito online apontam no mesmo sentido: cerca de metade dos inquiridos considerou que a sua participação no conflito teve efeitos negativos na sua saúde (tanto física como mental), e bem mais de metade afirmou que o tempo da comissão militar em África foi um período difícil de aguentar, de muita ansiedade e que deixou sequelas $(87 \%, 90 \%$ e $71 \%$, respetivamente).

É este contexto adverso que enquadra o uso de bebidas alcoólicas na Guerra Colonial Portuguesa e que, em última instância, explica a sua dimensão e contornos.

\section{Uso de bebidas alcoólicas}

Naturalmente que na Guerra Colonial Portuguesa os padrões de consumo de bebidas alcoólicas eram múltiplos, indo da abstinência ${ }^{13}$ ao consumo dito «excessivo»; igualmente heterogéneas eram as motivações e as circunstâncias de consumo. Ainda assim, toda a informação reunida aponta para que a ingestão de bebidas alcoólicas nos aquartelamentos portugueses fosse muito elevada, ao ponto de a embriaguez ser uma prática relativamente habitual e tendencialmente desvalorizada, tanto do ponto de vista disciplinar como do clínico.

De resto, em conflitos contemporâneos à Guerra Colonial Portuguesa, como a Guerra do Vietname (Kuzmarov, 2009), ou em conflitos anteriores, como I e a II Guerras Mundiais (Bergen-Cico, 2012), verificou-se também um consumo de álcool tendencialmente elevado. Tal não pode deixar de causar estranheza, dado tratar-se de uma substância que, a partir de determinado nível de consumo, limita as capacidades físicas e cognitivas, o que em contexto de guerra se pode revelar gravoso.

No entanto, ao longo da história, as substâncias psicoativas, em geral, e o álcool, em particular, circularam sempre livremente entre o meio militar, nomeadamente em contexto de conflito armado (Jones e Fear, 2011), sendo usadas de duas formas principais: como potenciadoras das capacidades militares (aumentando a agressividade ou combatendo o medo, por exemplo) ou como terapêuticas (atenuando o sofrimento físico ou, sobretudo, emocional) (Andreas, 2020; Kamienski, 2016).

Fosse qual fosse o propósito do uso, raros são os ex-combatentes que falam da sua participação na Guerra Colonial Portuguesa sem fazer menção às 
bebidas alcoólicas (com grande destaque para a cerveja e, no caso dos oficiais, também o whisky), tal era a sua importância no dia a dia. O álcool estava presente em todos os aquartelamentos portugueses, sendo ingerido às refeições ou fora delas, tanto em ocasiões especiais e momentos festivos como no mais banal dos dias.

Isso mesmo afirma o ex-cabo Eduardo Navarro, que esteve em Angola entre 1969 e 1971, na qualidade de enfermeiro militar. Seja pela sua formação, seja pelas responsabilidades que assumiu, é o informante que demonstrou maior reflexão analítica acerca do consumo de álcool na guerra:

\begin{abstract}
"Bebia-se por cam aradagem, por convivência, e porque o próprio clima convidava a fazê-lo. Poderia haver num ou noutro razões de ordem psicológica, de saudade da família, que nem sempre eram exteriorizadas. Bebia-se para comemorar o regresso de uma operação no mato, em que tudo tinha corrido pelo melhor, ou seja, sem mortos nem feridos; bebia-se porque se ia para uma ação no mato, e não se sabia quem, ou se, iria voltar; bebia-se porque poderia ser a última [vez]; bebia-se porque alguém fazia anos, ou porque alguém pagava umas rodadas; enfim, bebia-se porque estar vivo, por si só, já era um motivo."
\end{abstract}

De facto, tudo parecia favorecer a ingestão de bebidas alcoólicas, a começar pelo calor abrasador e pela escassez ou má qualidade da água disponível. De facto, muitos ex-combatentes referem que «a tropa não bebia água», antes cerveja, a bebida «emblemática» da Guerra Colonial Portuguesa, para usar a expressão de Luís Vasconcelos (2006: 71-72). Inclusivamente, a cerveja era, por vezes, usada para fazer a barba ou lavar os dentes (Aranha, 2005: 39).

As palavras dos ex-furriéis Joaquim Serpa, que esteve em Moçambique entre 1970 e 1972, e Alberto Monteiro, que esteve em Angola entre 1969 e 1971, respetivamente, são bem elucidativas:

“Copos, sempre houve. E cerveja, então, havia sempre. Não era tão cara quanto isso, e toda a gente bebia. Portanto, havia, digamos, um refúgio natural. O isolamento levava a que as pessoas... e às vezes até as deficiências da alimentação eram compensadas com o consumo de álcool. Eu próprio exagerava, e exagerei - nunca perdendo o norte, mas tornei isso uma form a de me alimentar ao pequeno-almoço, de acompanhar o almoço, etc. [...] O álcool era dia sim, dia sim. Eu não me lembro de, no mato, tomar algum pequeno- almoço que não fosse uma cerveja, com pão torrado, com manteiga, umas coisas do género".

"Principalmente consumia-se muita cerveja. Face à elevada temperatura ambiente (zon a de muito calor durante a maior parte do ano) e também devido 
ao isolamento no meio do mato e às duras realidades com que muitas vezes nos confrontávamos, a cerveja era a companhia amiga dos militares nas muitas horas e dias que passávamos lentamente nos quartéis".

Artur Duarte esteve em Angola no final da Guerra Colonial Portuguesa, servindo como furriel miliciano. Destaca-se como o informante que mais abertamente fala de transtornos emocionais e consequentes problemas mentais, nomeadamente ao nível da ansiedade e do que é normalmente designado stress pós-traumático:

"Eu mais que dupliquei o consumo de álcool e de outras coisas porque o tempo que se passava nos aquartelamentos, entre operações, é muito difícil de definir. [...] O clima era tal que, para além da ansiedade, para além de eu saber que amanhã ou depois de amanhã parto para uma operação de três dias, tudo era perigoso. Tudo isso, aquele isolamento... Andava tudo apanhado".

Mesmo com todos os excessos e consequências negativas, nomeadamente ao nível do comportamento e da disciplina, a verdade é que, para a administração militar, as bebidas alcoólicas eram consideradas importantes para o moral das tropas. A prova disso é que a logística de guerra se encarregava de as distribuir, juntamente com outros bens ou produtos considerados vitais, como munições, armamento, correspondência, alimentos ou medicamentos, em todos os aquartelamentos portugueses situados nos territórios em guerra, por mais remotos e isolados que fossem; além disso, eram vendidas a baixo custo. As bebidas alcoólicas nunca faltavam e, por norma, os quartéis dispunham de locais próprios onde podiam ser adquiridas e consumidas, designadamente messes, bares ou cantinas, espaços de grande importância social.

Em aerogramas enviados da guerra, o ex-alferes José Niza (2012), que esteve em Angola enquanto médico militar, dá conta da reação que, em 1971, as tropas tiveram perante a decisão governamental de limitar o acesso às bebidas alcoólicas nos quartéis portugueses em África. Esta medida provocou tanta agitação e contestação entre os militares, que acabou por ser revertida menos de três semanas depois.

Não surpreende, portanto, que o panorama etílico nos aquartelamentos portugueses fosse intenso, sendo o consumo de bebidas alcoólicas uma prática comum entre todo o tipo de militares: praças, sargentos e oficiais, operacionais e não operacionais, milicianos ou pertencentes ao Quadro Permanente, enquadrados em tropas regulares ou irregulares. A confirmá-lo, a esmagadora maioria dos respondentes ao inquérito online considera que o consumo de bebidas alcoólicas, e de cerveja em particular, entre as tropas portuguesas durante a guerra de África era generalizado (61\%) ou frequente (33\%), pelo que apenas uma pequena minoria é da opinião de que era raro (5\%) ou inexistente (1\%). 
Os episódios de embriaguez no interior dos aquartelamentos eram muito recorrentes, não obstante tal constituir um evidente óbice ao desempenho das funções militares, razão pela qual o Regulamento Disciplinar Militar (artigo 24) proibia expressamente talesse comportamento. De um modo geral, quanto mais difícil era a situação (não apenas do ponto de vista militar, mas também, por exemplo, em relação ao isolamento), maior era o consumo de bebidas alcoólicas. Quando as circunstâncias ou as condições de vida se tornavam mais difíceis, incluindo ocasiões em que as saudades da família aumentavam - como a véspera de Natal ou a noite da passagem de ano (Niza, 2012; Pereira, 2011) -, a embriaguez alcoólica tornava-se mais prevalente. Na Guerra Colonial Portuguesa, parece certa a existência de uma relação direta entre o sofrimento social (Alexander, 2008; Kleinman, Das \& Lock, 1997) e o uso de bebidas alcoólicas, o que provavelmente explica a tolerância demonstrada pelas chefias perante os excessos alcoólicos, certamente na lógica de que a um morto nada se recusa.

É também nesse sentido que podem ser interpretadas as palavras de Avelino Nunes, um estudante de Belas-Artes que foi recrutado para cumprir serviço militar em Moçambique entre 1969 e 1972, na condição de furriel sapador, e dos atrás apresentados Miguel Raposo e Luís Leal, respetivamente:

"Quase toda a gente bebia. Eu nunca fui bebedor, pá, e bebia. Era um escape. Para os gajos que andavam no mato, era um escape. Por duas razões: por um lado, porque estavam isolados, e, por outro lado, porque sofriam as consequências da guerra. Então tinham que desopilar de qualquer maneira. O u fazendo partidas uns aos outros, ou bebendo. Para os outros gajos que não saíam do quartel, e que viveram 16 meses ali fechados entre arame farpado, também era um escape".

"Nós bebiamos, bebíamos. Naturalmente porque era uma forma de acalmar, de esquecer, de recuperar, retemperar até. Mas, quando partíamos para combate, tínhamos de ter a certeza que estávamos lúcidos. Chegávamos de uma operação, enfim, como qualquer outra situação, porque precisávamos de reagir e de recuperar de stress, e o álcool ajudava. O álcool desempenhava um papel, digamos, de estabilizador. Reequilibrar um pouco os ânimos. Porque situações de combate provocavam grande stress, e o álcool, de algum modo, aliviava. Era uma form a de esquecer. E isso era recorrente".

"O álcool estava muito presente, estava. Eu digo-lhe já, eu hoje bebo à refeição um copo de vinho ou dois. Mas eu lá quase todos os dias me embebedava. Depois cantávamos aquela canção do Paco Bandeira, «lá longe, onde o sol castiga mais». A quilo para nós era um escape. [...] Era mais à noite porque a malta durante o dia andava no mato. Depois, quando regressava à noite, tomava 
um banhinho e tal, ia para as casernas, para os petiscos [...] «vai mais uma Laurentina, vai mais outra e outra». Às duas por três já estava tudo bêbedo".

\section{Discussão}

O consumo de bebidas alcoólicas por parte dos militares durante a Guerra Colonial Portuguesa não pode obviamente ser desligado de algumas condicionantes anteriores ao serviço militar. Afinal, os militares eram maioritariamente jovens com idade a rondar os 20 anos, pouco letrados e de origem rural, num país onde, há muito, o álcool (e o vinho, em particular) era visto como um bem de grande importância social. É preciso não esquecer que, à época, a propaganda do regime dizia que «beber vinho é dar pão a um milhão de portugueses», e, no mundo rural, nomeadamente entre elementos do sexo masculino, era habitual a ingestão de bebidas alcoólicas iniciar-se bem antes dos 18 anos, a idade mínima legal nos dias de hoje.

No entanto, em comparação com a vida civil anterior à guerra, nos territórios africanos, alteraram-se os padrões de consumo e também as próprias motivações e contextos de consumo, aspetos que estão interligados. Como dito atrás, a Guerra Colonial Portuguesa foi, a vários níveis, um tempo de experimentação, em que muita coisa se vivenciou pela primeira vez, incluindo o uso de substâncias psicoativas. Embora o álcool não fosse propriamente um produto que os militares desconhecessem, bem pelo contrário, durante a guerra a ingestão de bebidas alcoólicas foi assumindo novos significados e adquirindo maior dimensão. Como se pode ler nas narrativas destes ex-militares, o consumo de álcool tornou-se mais prevalente e mais frequente, tendo muitos deles adotado novos padrões de consumo - por exemplo, beber um par de cervejas ao pequeno-almoço ou 2 ou 3 antes de adormecer, o que, de acordo com a perspetiva clínica, pode indiciar um nível de consumo «nocivo».

De facto, na altura da Guerra Colonial Portuguesa, quem aplicasse um instrumento de rastreio aos militares portugueses envolvidos no conflito certamente e seguisse os critérios de diagnóstico, concluiria que a maioria apresentava padrões de consumo «nocivo» e que não eram poucos os que se encontravam na condição de dependência ou doença alcoólica, nomeadamente os que se apresentavam embriagados em público de uma forma recorrente.

No entanto, tanto estes padrões de consumo como a embriaguez eram comportamentos vistos comos «normais» e dificilmente eram encarados a partir de uma perspetiva clínica e do conceito de alcoolismo. Prova disso são as cartas que o então médico José Niza (2012) enviou de Angola, dando conta de como, depois de muito esforço, conseguiu encaminhar o capitão da sua companhia para o Hospital de Luanda com o diagnóstico de doença alcoólica. O episódio revela bem como, naquele contex to, o uso excessivo de bebidas alcoólicas 
não era entendido como um problema de saúde, pelo que só em casos extremos conduzia a um processo disciplinar e, no limite, ao tratamento clínico e à evacuação. Por regra, mesmo quando se reconhecia que o álcool contribuía para comportamentos considerados incorretos (como episódios de incúria, infrações à conduta ou casos de indisciplina e insubordinação), tendia-se a desvalorizar o seu lado problemático, sendo o consumo «excessivo» olhado como algo que era fruto do contexto, das circunstâncias, da mentalidade da época e até da própria juventude dos militares.

Assim sendo, o que é a todo o momento salientado é a importância terapêutica do álcool naquele contexto, algo entendido como vital para o bem-estar e o ânimo das tropas, na medida em que ajudava a lidar com as adversidades inerentes à experiência de guerra, que é, por definição, uma experiência-limite

Num cenário de guerra, para mais nas condições atrás descritas, o álcool era visto como algo que tinha uma ação positiva sobre o estado emocional e, nesse sentido, um bem indispensável à boa saúde dos combatentes, a par de outras coisas que ajudavam a passar o tempo, a dar sentido à existência e a resistir ao desânimo, como, por exemplo, o convívio com os camaradas ou a correspondência com familiares e madrinhas de guerra. Nas palavras dos próprios ex-militares, no contexto de guerra, beber álcool era uma forma de «escape», de «acalmar», «retemperar», «recuperar», «esquecer», «reequilibrar» ou «aliviar», atuando como «tranquilizante» ou «anestesia». Para as autoridades militares, o álcool era um bem que permitia que as tropas se mantivessem funcionais e aptas a combater - isto é, sem se afundarem no desânimo, dado que tudo se passava num cenário que convidava ao colapso.

Em suma, para os soldados da Guerra Colonial Portuguesa, beber álcool era uma forma de lidar com uma realidade marcada pela violência do quotidiano, pelo isolamento e pelo sofrimento e, assim, conseguir manter o controlo. Pela mesma razão, para os comandantes e para a administração militar, as bebidas alcoólicas eram um instrumento de controlo social, o que explica que fossem distribuídas sem restrição por todos os aquartelamentos a baixo preço, ou, no caso do vinho, de forma gratuita às refeições.

\section{Conclusão}

O modo como os ex-combatentes da Guerra Colonial Portuguesa falam do consumo de bebidas alcoólicas durante o conflito revela que este consumo tinha sobretudo uma motivação «terapêutica», nomeadamente como mecanismo de adaptação a circunstâncias muito difíceis de suportar e como «alívio emocional», para usar a expressão de alguns informantes. Não é certamente por acaso que os informantes que reconhecem ter bebido de maneira «excessiva» são também os que mais falam do sofrimento por que passaram. Mas, 
até por via da herança cultural, o álcool é uma substância usada com múltiplos propósitos, pelo que nos aquartelamentos portugueses a ele se recorria como «lubrificante social», designadamente para potenciar a diversão em momentos festivos ou para reforçar a camaradagem.

O caso dos militares portugueses que participaram na Guerra Colonial Portuguesa ilustra bem como o consumo de álcool deriva necessariamente do contex to e das circunstâncias sociais, na medida em que é aprendido, conceptualizado, enquadrado e regulado no plano societal, e também do conjunto de motivações, expectativas e crenças dos consumidores - isto é, o set e o setting, para usar os conceitos propostos por Norman Zinberg (1984). Dito de outra forma, este é também um exemplo empírico de como o que é considerado «aceitável», «normal» ou «patológico» depende mais das normas e da realidade sociocultural do que de critérios objetivos e mensuráveis, ainda que a perspetiva biomédica nem sempre reconheça isso.

Pelo contrário, a ideia subjacente à perspetiva antropológica é a de que conhecer as características principais da Guerra Colonial Portuguesa e os traços mais marcantes da experiência por que passaram os militares portugueses que participaram no conflito permite perceber melhor as motivações e os propósitos dos consumos de bebidas alcoólicas que aí tiveram lugar, por mais excessivos que fossem. No que ao álcool diz respeito, o que se passou na Guerra Colonial Portuguesa é pontuado por ironias e paradoxos: como é possível que as bebidas alcoólicas - que, a partir de certo nível de ingestão, têm um efeito disruptivo - fossem consumidas como mecanismo de adaptação e como forma de evitar o descontrolo? Como é possível que o consumo de bebidas alcoólicas fosse incentivado pela máquina militar, sabendo-se que o álcool está frequentemente associado a problemas de comportamento e que o meio militar é, por definição, uma instituição que assenta num rigoroso respeito pelas regras e pela autoridade? Como é possível que o consumo de uma mesma substância psicoativa fosse simultaneamente causa e sintoma da dimensão problemática? Como é possível que a embriaguez, mesmo quando era recorrente e reiterada, fosse desvalorizada e tolerada por todos, mesmo por oficiais superiores, não obstante constituir uma clara infração ao regulamento militar em vigor? Como é possível que tantos ex-militares tenham conseguido reduzir drasticamente a ingestão de bebidas alcoólicas assim que se viram livres da guerra, sabendo-se que, de acordo com os critérios clínicos, se encontravam na condição de dependência alcoólica ou em risco disso?

Como foi argumentado, a resposta a estas perguntas reside no plano social e não na dimensão biológica, e quem a procurar nas propriedades farmacológicas da substância psicoativa em causa ou nas características individuais dos consumidores, incluindo as suas predisposições genéticas, não a vai encontrar. 


\section{Referências bibliográficas}

AFONSO, Aniceto, GOMES, Carlos Matos (2000), Guerra Colonial, Lisboa, Editorial Notícias. ALEXAN DER, Bruce (2008), The Globalisation of Addiction. A Study in Poverty of the Spirit, Oxford, Oxford University Press.

AN DREAS, Peter (2020), Killer High. A History of War in Six Drugs, Oxford, Oxford University Press.

ANTUNES, António Lobo (2005), D'este Viver Aqui Neste Papel Descripto, organizado por Maria José Lobo Antunes e Joana Lobo Antunes, Lisboa, Dom Quixote.

AN TUNES, José Freire (1995), A Guerra de África: 1961-1974, Lisboa, Círculo de Leitores.

AR AN H A, Eduardo Brito (2005), Um Barco Fardado, Lisboa, Roma Editora.

BERGEN-CICO, Dessa (2012), War and Drugs: The Role of Military Conflict in the Development of Substance Abuse, Boulder, Paradigm Publishers.

BERNARD, H. Russell (2006), Research Methods in Anthropology. Qualitative and $Q$ uantitative Approaches, Lanham, Altamira Press.

CALAdO, Vasco (2016), "As Drogas em Combate: Usos e Significados das Substâncias Psicoativas na Guerra Colonial Portuguesa", Etnográfica, vol. 20 (3), 471-494.

CALAdo, Vasco (2019), As Drogas em Combate: Usos e Significados das Substâncias Psicoativas na Guerra Colonial Portuguesa [tese de Doutoramento], Lisboa, ISCTE-IUL.

CAMPOS, Ângela (2017), An Oral History of the Portuguese Colonial War. Conscripted Generation, Cham, Springer International Publishing.

CARDinA, Miguel, MARTINS, Bruno Sena (orgs.) (2018), As Voltas do Passado. A Guerra Colonial e as Lutas de Libertação, Lisboa, Tinta-da-China.

DENZIN, Norman (2009) [1970], The Research Act. A Theoretical Introduction to Sociological Methods, New Brunswick, Aldine Transaction.

DEVillard, M. José, MUDANÓ, Adela, PAZOS, Álvaro (2012), “Apuntes Metodológicos sobre la Conversación en el Trabajo Etnográfico", Política Y Sociedad, vol. 49, (2), 353-369.

FERNANDES, Luís, CARVALHO, Maria Carmo (2000), "Por Onde Anda o que se Oculta: o Acesso a Mundos Sociais de Consumidores Problemáticos de Drogas através do Método do 'Snowball'”, Toxicodependências, 6 (3), 17-28.

FON TAN A, Andrea, FREY, James (2005) [1994], “The Interview”, in Norman Denzin e Yvonna Lincoln (orgs.), The Sage Handbook of Q ualitative Research (3. a edição), Thousand Oaks, Sage, 361-376.

GRIFFITHS, Paul, MOUN TENEY, Jane (2010), “Drug Trend Monitoring”, in Peter G. Miller, John Strang e Peter M. Miller (orgs.), Addiction Research Methods, Oxford, Wiley-Blackwell, 337-354.

HEATH, Dwight (1987), "Anthropology and Alcohol Studies: Current Issues", Annual Review of Anthropology, 16, 99-120.

HEATH, Dwight (2000), Drinking Occasions: Comparative Perspectives on Alcohol and Culture, Philadelphia, Taylor and Francis.

HORST, Heather, MILLER, Daniel (orgs.) (2012), Digital Anthropology, Londres, Berg.

HUNT, Geoffrey, BARKER, Judith (2001), "Socio-Cultural Anthropology and Alcohol and Drug Research: Towards a Unified Theory”, Social Science \& Medicine, 53, 165-188.

JONES, Edgar, FEAR, Nicola (2011), "Alcohol Misuse within the Military: A Review", International Review of Psychiatry, 23, 166-172.

KAM IEN SKI, Lukasz (2016), Shooting Up: A Short History of Drugs and War, Oxford, Oxford University Press. 
KLEINMAN, Arthur, DAS, Veena, LOCK, Margaret (orgs.) (1997), Social Suffering, Berkeley, University of California Press.

KUZM AROV, Jeremy (2009), The Myth of the Addicted Army. Vietnam and the Modern War on Drugs, Boston, University of Massachusetts Press.

LEVINE, Harry (1978), “The Discovery of Addiction”, Journal of Studies on Alcohol, 39, 143-174.

MANO, Piedade (1990), "O Valor e o Papel do Álcool na Família”, in AA.VV, A Sociologia e a Sociedade Portuguesa na Viragem do Século: Actas do I Congresso Português de Sociologia, Lisboa, Editorial Fragmentos, 259-267.

MARTINS, Bruno Sena (2015), "Violência Colonial e Testemunho: Para uma Memória PósAbissal", Revista Crítica de Ciências Sociais, 106, 105-126.

NIZA, José (2012), Golden Gate. Um Quase Diário de Guerra, Alfragide, Dom Quixote.

OEIRAS, Luís (2009), Mueda-Lua, Lisboa, Roma Editora.

PEREIRA, Rogério (2011), Almas que Não Foram Fardadas, Oeiras, Espaço e Memória Associação Cultural de Oeiras.

PIN K, Sarah et al. (2015), Digital Ethnography: Principles and Practice, Thousand Oaks, Sage.

PINTO, Augusto et al., (2016), Perturbação do Uso do Álcool, Revista Portuguesa de Farmocoterapia, 8 (1), 34-43.

REINARM AN, Craig, GRANFIELD, Robert (2015), “Addiction is Not Just a Brain Disease: Critical Studies of Addiction”, in Robert Granfield e Craig Reinarman (orgs.), Expanding Addiction: Critical Essays, New York, Routledge, 1-21.

SCHNEIDER, Joseph (2015), "Deviant Drinking as Disease. Alcoholism as a Social Accomplishment", in Robert Granfield e Craig Reinarman (orgs.), Expanding Addiction: Critical Essays, New York, Routledge, 51-61

SILVA, Tiago Matos (2007), "Exilados em Casa. Os Veteranos da Guerra Colonial e os Limites da "Nação", A rquivos da Memória. Temas e Problemas em Antropologia, 1 (1), 31-39.

TEIXEIRA, Rui de Azevedo (1998), A Guerra Colonial e o Romance Português, Lisboa, Editorial Notícias.

VASCONCELOS, Luís Almeida (2006), sem título, Etnográfica, número especial.

ZIN BERG, Norman (1984), Drug, Set and Setting. The Basis for Controlled Intoxicant Use, New Haven, Yale University Press.

- Receção: 14-04-2020

- Aprovação: 04-02-2021 